\title{
Morphometric Analysis of the Orbit in Dry Skulls of North Indian Population: A Direct Measurement Study
}

\author{
Dalvinder Singh $^{1 *}$, Vaishali Gandhi ${ }^{2}$ and Sonu ${ }^{3}$ \\ ${ }^{1}$ Professor, Department of Anatomy, Faculty of Dentistry, Jamia Millia Islamia, Delhi- 110025, India \\ ${ }^{2}$ Assistant Professor, Department of Anatomy, Dasmesh Institute of Research and Dental Sciences, Faridkot, Punjab- 151203, India \\ ${ }^{3}$ Senior Resident, Department of Anatomy, University College of Medical Sciences \& Guru Teg Bahadur Hospital, Shahdara, Delhi- 110095, India
}

DOI: $\underline{10.36348 / \text { sjpm.2020.v05i04.004 }}$

| Received: 14.04.2020 | Accepted: 24.04.2020 | Published: 29.04.2020

*Corresponding author: Dr. Dalvinder Singh

\section{Abstract}

Introduction: Human orbit is a complex anatomical region, comprising visual apparatus along with its neurovascular structures. Morphometric analysis of orbit is of significant value for anthropologists, anatomists, forensic experts and surgeons. The objective of this study was to provide gender-related data on various orbital parameters in the North Indian population, and to compare the results with previous authors. Materials and Methods: The orbital dimensions of 86 dry adult skulls (45 males and 41 females) were used for direct measurement with vernier caliper. The calculation was carried out on both the right and the left sides. All the data obtained were tabulated and statistically analyzed. Results: The mean orbital height for males and females was $32.53 \pm 2.00 \mathrm{~mm}$ and $32.43 \pm 1.57 \mathrm{~mm}$ while the mean orbital width was $39.98 \pm 1.81 \mathrm{~mm}$ and $39.37 \pm 1.65 \mathrm{~mm}$, respectively. The mean volume of the bony orbit was $26.09 \pm 2.15 \mathrm{ml}$ in males, and $24.04 \pm 2.30 \mathrm{ml}$ in females. Orbital index was calculated by using the formula $\mathrm{Ht} / \mathrm{Br} \times 100$. The mean orbital index was $81.51 \pm 6.11 \mathrm{~mm}$ and $82.54 \pm 5.38 \mathrm{~mm}$ in males and females respectively, which classified both genders in the microseme category of orbit. There was no statistically significant difference observed between the right and left side of the orbital parameters. Conclusion: Comparison of findings with earlier research reveals that the anatomical character of the orbital cavity differs greatly, not only because of the diversity of the parameters used, but also because of ethnic variations, different methods of measurement and sample size. Data collected in the present investigation could serve as a baseline orbital morphometric data for the North Indian population, which is very useful during plastic surgery, maxillofacial and neurosurgery, as well as in forensic science.

Keywords: Orbit, North Indian skulls, morphometry, Orbital index.

Copyright @ 2020: This is an open-access article distributed under the terms of the Creative Commons Attribution license which permits unrestricted use, distribution, and reproduction in any medium for non-commercial use (NonCommercial, or CC-BY-NC) provided the original author and sources are credited.

\section{INTRODUCTION}

The orbits are craniofacial bony sockets positioned on either side of the sagittal plane of skull, comprising the visual apparatus including the eye ball, related muscles, nerves, vessels, lacrimal apparatus, fascial strata and fat. They enable the visual axis to be oriented correctly, and establish the spatial relation between the eyes which is important for both binocular vision and eye motion in conjugation $[1,2]$.

Morphometric parameters of orbit are of significant value in many specialties, including ophthalmology, optometry, oculoplastic surgery, traumatology and oral maxillofacial surgery. Orbital indices are also an important predictor for the assessment and treatment of craniofacial syndromes and post-traumatic deformities. This is also relevant in various other fields such as analysis of fossil records, classification of skulls in forensic medicine, explanation of trends in evolutionary and ethnic differences. Therefore, detailed knowledge of the orbital anatomy is essential [3-6]. Since the morphology of the orbit seems to be dependent on the population as indicated by the previous authors [3, 7-10], the present study was undertaken to provide morphometric orbital data in the dry skulls of the North Indian population.

\section{MATERIALS AND METHODS}

The present study sample consists of 86 dry adult human skulls of unknown sex. None of the skulls had any injury, congenital deformity or artifacts. On the basis of morphology, 45 male and 41 female skulls were differentiated [11-13]. 


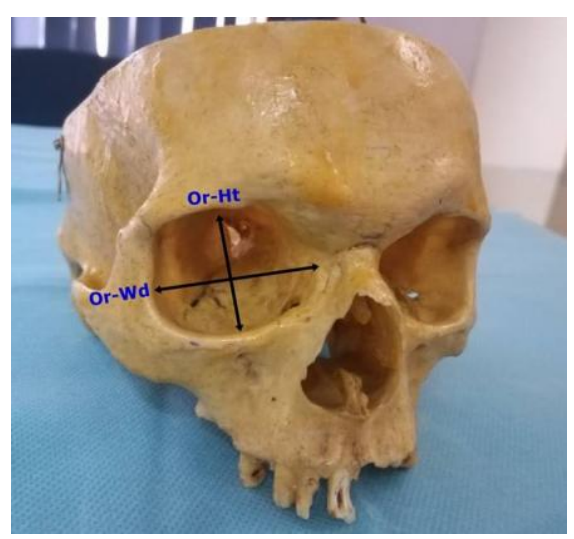

Fig-1: Photograph showing the measurements of orbital width (Or-Wd) and orbital height (Or-Ht)

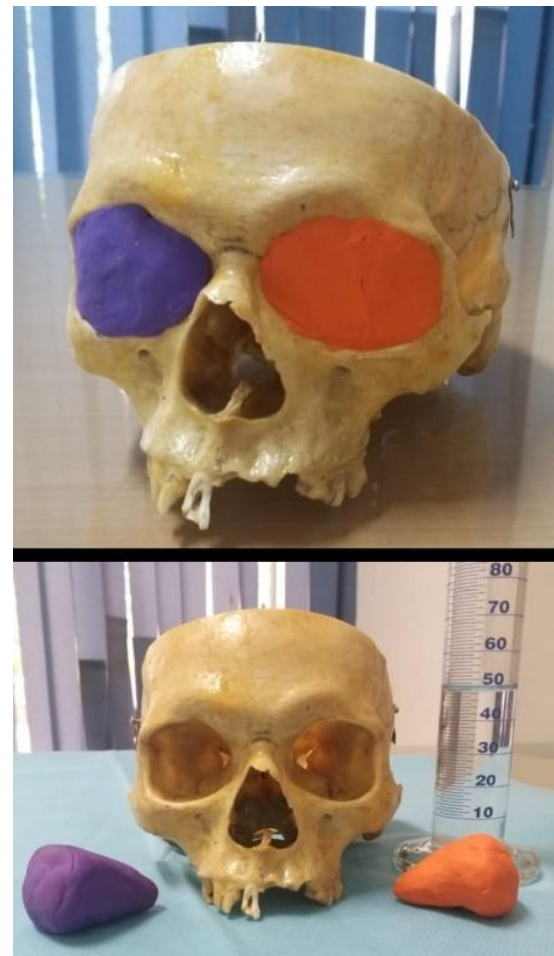

Fig-2: Measurement of bony orbital volume using the water filling method.

Measurements were calculated for the dimensions of the orbits (Figure-1) placing the skull in
Frankfurt's horizontal plane $[11,14,15]$. The analyzed parameters were:

a. Orbital height $(\mathrm{Or}-\mathrm{Ht}) \rightarrow$ The distance between upper and lower margins of the orbital cavity perpendicular to the horizontal axis of the orbit was calculated.

b. Orbital width (Or-Wd) $\rightarrow$ Measured from the point on the medial margin of the orbit where the frontal, lacrimal and maxillary bones intersect (Dacryon point) to the junction between the lateral orbital margin and the horizontal line which divides the orbital opening into two equal parts (Ectoconchion point).

c. Orbital index (Or-I) $\rightarrow$ Orbital height / orbital width $\mathrm{x} 100$.

d. Orbital volume (Or-Vol) $\rightarrow$ The water displacement method was used to determine the volume of the bony orbit. Briefly, for the bony orbits three-dimensional models of plasticine were made. Each model was immersed in a graduated cylinder filled with distilled water. The displaced water was measured, representing the orbital volume (Figure-2).

All the measurements were taken bilaterally and the data obtained were tabulated and statistically analyzed. Paired t-test was done to assess the statistical significance of all orbit parameters for sides and gender. Differences were considered statistically significant at $\mathrm{p}<0.05$.

\section{RESULTS}

The present study was conducted in 86 adult skulls, of which 45 were males and 41 were females. Table 1 displays the measured data for the right and left orbits in the male skulls. The mean orbital height was $32.90 \pm 1.95 \mathrm{~mm}$ on the right and $32.16 \pm 1.99 \mathrm{~mm}$ on the left side and the mean orbital width was $40.16 \pm 1.80$ $\mathrm{mm}$ on the right and $39.80 \pm 1.80 \mathrm{~mm}$ on the left side. The mean volume of the bony orbit was $26.21 \pm 2.13 \mathrm{ml}$ on the right side and $25.96 \pm 2.16 \mathrm{ml}$ on the left side.

Table-1: Descriptive data and statistical significance of orbital dimensions in right and left male orbits

\begin{tabular}{|l|l|l|l|}
\hline \multirow{2}{*}{ Parameter } & Right & Left & \multirow{2}{*}{ p-value } \\
\cline { 2 - 3 } & Mean \pm SD & Mean \pm SD & \\
\hline Orbital height $(\mathrm{mm})$ & $32.90 \pm 1.95$ & $32.16 \pm 1.99$ & $0.17, \mathrm{~ns}^{*}$ \\
\hline Orbital width $(\mathrm{mm})$ & $40.16 \pm 1.80$ & $39.80 \pm 1.80$ & $0.47, \mathrm{~ns}$ \\
\hline Orbital volume $(\mathrm{ml})$ & $26.21 \pm 2.13$ & $25.96 \pm 2.16$ & $0.67, \mathrm{~ns}$ \\
\hline Orbital index & $82.09 \pm 6.19$ & $80.94 \pm 5.98$ & $0.49, \mathrm{~ns}$ \\
\hline
\end{tabular}

$\mathrm{P}<0.05$ was considered statistically significant. ns*: not statistically significant.

Table-2 displays the measured data for the right and left orbits in the female skulls. The mean height on the right side was $32.05 \pm 1.55 \mathrm{~mm}$ and on the left was $32.82 \pm 1.50 \mathrm{~mm}$ and the mean width on the right side was $39.06 \pm 1.46 \mathrm{~mm}$ and on the left was $39.68 \pm 1.76 \mathrm{~mm}$. The mean volume of bony orbit measured was $24.07 \pm 2.20 \mathrm{ml}$ and $24 \pm 2.39 \mathrm{ml}$, respectively, on the right and left sides. All of the measured parameters were higher on the right side than on the left side in males and females with no statistically significant differences $(p<0.05)$. 
Table-2: Descriptive data and statistical significance of orbital dimensions in right and left female orbits

\begin{tabular}{|l|l|l|l|}
\hline Parameter $(\mathbf{m m})$ & Right & Left & p-value \\
\cline { 2 - 3 } & Mean \pm SD & Mean $\mathbf{S D}$ & \\
\hline Orbital height $(\mathrm{mm})$ & $32.05 \pm 1.55$ & $32.82 \pm 1.50$ & $0.07, \mathrm{~ns} *$ \\
\hline Orbital width $(\mathrm{mm})$ & $39.06 \pm 1.46$ & $39.68 \pm 1.76$ & $0.16, \mathrm{~ns}$ \\
\hline Orbital volume $(\mathrm{ml})$ & $24.07 \pm 2.20$ & $24 \pm 2.39$ & $0.91, \mathrm{~ns}$ \\
\hline Orbital index & $82.18 \pm 5.00$ & $82.89 \pm 5.71$ & $0.63, \mathrm{~ns}$ \\
\hline
\end{tabular}

$\mathrm{P}<0.05$ was considered statistically significant. ns*: not statistically significant.

The orbital index was calculated using orbital height and width. The mean orbital index in males was $82.09 \pm 6.19 \mathrm{~mm}$ on the right and $80.94 \pm 5.98 \mathrm{~mm}$ on the left side, in females it was $82.18 \pm 5 \mathrm{~mm}$ on the right and $82.89 \pm 5.71 \mathrm{~mm}$ on the left side.
Table- 3 compares the sum mean of parameters between males and females (right and left side). There was no statistically significant differences observed in measured parameters between males and females, except for the orbital volume where the difference was statistically significant $(\mathrm{p}<0.05)$.

Table-3: Descriptive data and statistical significance for orbital dimensions in total male and female orbits

\begin{tabular}{|l|l|l|l|}
\hline Parameter $(\mathbf{m m})$ & Male & Female & \multirow{2}{*}{ p-value } \\
\cline { 2 - 3 } & Mean \pm SD & Mean \pm SD & \\
\hline Orbital height $(\mathrm{mm})$ & $32.53 \pm 2.00$ & $32.43 \pm 1.57$ & $0.79, \mathrm{~ns}$ \\
\hline Orbital width $(\mathrm{mm})$ & $39.98 \pm 1.81$ & $39.37 \pm 1.65$ & $0.07, \mathrm{~ns}$ \\
\hline Orbital volume $(\mathrm{ml})$ & $26.09 \pm 2.15$ & $24.04 \pm 2.30$ & $0.00, \mathrm{~s}^{* *}$ \\
\hline Orbital index & $81.51 \pm 6.11$ & $82.54 \pm 5.38$ & $0.35, \mathrm{~ns}$ \\
\hline
\end{tabular}

$\mathrm{P}<0.05$ was considered statistically significant. ns*: not statistically significant, $\mathrm{s} * *$ : statistically significant.

The mean orbital index was $81.51 \pm 6.11 \mathrm{~mm}$ and $82.54 \pm 5.38 \mathrm{~mm}$ for males and females, respectively, indicating that the North Indian orbital group is microseme type.

\section{DISCUSSION}

Each orbit is shaped like a pyramid, with its apex directed posteriorly at optical canal and its base anterolaterally is formed by the orbital margin [1, 2]. Martins et al., described the anatomical characteristics of the orbit and revealed that the structures in the orbit consist of seven bones, seven muscles and seven nerves [16]. Orbital morphometric analysis will also play an essential role in particular surgeries in the orbit, for instance, orbital decompression, enucleation, exenteration, optic nerve decompression and vascular ligation [3-6].

Gosavi et al., evaluated 64 skulls from Maharashtra region and reported that the mean orbital height was $31.97 \pm 2.39 \mathrm{~mm}$ and $32.66 \pm 2.71 \mathrm{~mm}$ on the right and the left sides respectively, and the orbital width was $39.71 \pm 2.65 \mathrm{~mm}$ on the right side and $39.22 \pm 2.5 \mathrm{~mm}$ on the left side [17]. According to the study of Kaur in Punjab, India, the mean orbital height was $31.9 \mathrm{~mm} \pm 2.2 \mathrm{~mm}$ and $32.2 \mathrm{~mm} \pm 1.8 \mathrm{~mm}$ respectively for right and left sided orbital cavity. And the mean orbital width was $39.7 \mathrm{~mm} \pm 2.2 \mathrm{~mm}$ and 38.8 $\mathrm{mm} \pm 3.1 \mathrm{~mm}$ respectively for the right and the left orbital cavity [18]. The study of Lal et al. in Sri Lankan skulls showed that the mean orbital height in males on the right and left sides was $32.24 \pm 2.19 \mathrm{~mm}$ and $32.74 \pm 1.96 \mathrm{~mm}$, with a width of $41.47 \pm 1.94$ and $40.63 \pm 1.9 \mathrm{~mm}$ respectively. In females on the right and the left side, the mean orbital height was $32.35 \pm 1.93$ and $32.65 \pm 1.94 \mathrm{~mm}$ while the width was $38.91 \pm 2.39$ and $38.27 \pm 2.1 \mathrm{~mm}$ respectively [19]. In a study on the South Indian population recorded that, the orbital height was $36.2 \pm 2.3 \mathrm{~mm}$ in males and $34.5 \pm 2 \mathrm{~mm}$ in females while the orbital width in males was $42.9 \pm 2.7 \mathrm{~mm}$ and in females was $40.5 \pm 2.4 \mathrm{~mm}[20]$. In the province of West Bengal, a populated region in eastern India, Sarkar et al. has examined 92 skulls and has observed that the orbital height was $34.97 \pm 3.86 \mathrm{~mm}$ on the right and $35.22 \pm 3.84 \mathrm{~mm}$ on the left side, while the orbital width was $39.87 \pm 4.06 \mathrm{~mm}$ on the right and $39.93 \pm 3.97$ $\mathrm{mm}$ on the left side in males. In females, orbital height was $35.63 \pm 5.17 \mathrm{~mm}$ on the right and $35.86 \pm 5.33 \mathrm{~mm}$ on the left side, while orbital width was $39.01 \pm 4.92 \mathrm{~mm}$ on the right and $39.17 \pm 4.92 \mathrm{~mm}$ on the left side [21]. According to Fetouh et al. who examined 52 adult Egypt skulls, orbital height in males on the right side was $35.83 \pm 1.23 \mathrm{~mm}$ while on the left side it was $35.27 \pm 1.35 \mathrm{~mm}$ and mean orbital width on the right side was $43.62 \pm 1.13 \mathrm{~mm}$ and on the left side was $42.6 \pm 0.94 \mathrm{~mm}$. The mean orbital height for the female skulls was $35.53 \pm 0.95 \mathrm{~mm}$ on the right side and $34.71 \pm 1.12 \mathrm{~mm}$ on the left side and the orbiting width on the right side $42.75 \pm 1.35 \mathrm{~mm}$ and $42.0 \pm 1.37 \mathrm{~mm}$ on the left side [4]. In 2017, Yonguc et al., measured 74 adult West Anatolian dry skulls and recorded an orbital height of $34.4 \pm 2.3 \mathrm{~mm}$ and $34.1 \pm 2.2 \mathrm{~mm}$ on the right and left sides respectively, with an orbital width of $37.1 \pm 3.5 \mathrm{~mm}$ on the right and $37 \pm 3.4 \mathrm{~mm}$ on the left side [22]. In the present study, the orbital height observed in males was $32.90 \pm 1.95 \mathrm{~mm}$ on the right and $32.16 \pm 1.99 \mathrm{~mm}$ on the left side and in females it was $32.05 \pm 1.55 \mathrm{~mm}$ and $32.82 \pm 1.50 \mathrm{~mm}$ on the right and left side respectively. The orbital width for males was 
$40.16 \pm 1.80 \mathrm{~mm}$ on the right and $39.80 \pm 1.80 \mathrm{~mm}$ on the left side and for females it was $39.06 \pm 1.46 \mathrm{~mm}$ and $39.68 \pm 1.76 \mathrm{~mm}$ on the right and left sides respectively. The overall mean orbital height was $32.53 \pm 2.00 \mathrm{~mm}$ in males and $32.43 \pm 1.57 \mathrm{~mm}$ in females while the mean orbital width was $39.98 \pm 1.81 \mathrm{~mm}$ for males and $39.37 \pm 1.65 \mathrm{~mm}$ for females. The right and left orbital heights and widths were not statistically significantly different, indicating left and right symmetry. These values are in congruence with Gosavi, Kaur and Lal, but, Fetouh and Mekala observed higher values in their study. The differences observed could be due to variation in sample size, method of study and geographical, environmental and genetic diversity.

Quantitative determination of orbital volume is valuable for the assessment and management of a number of conditions affecting the orbit [14, 23-25]. Fetouh et al. in Egyptian skulls recorded the mean right and left bony orbital volumes as $29.07 \pm 1.64 \mathrm{ml}$ and $28.15 \pm 1.32 \mathrm{ml}$ in males and $26.16 \pm 1.23 \mathrm{ml}$ and $25.21 \pm 1.03 \mathrm{ml}$ in females, respectively [4]. In a study in Turkey reported that the mean orbital volume in males was $32.21 \pm 1.55 \mathrm{~cm}^{3}$ and in females was $31.11 \pm 1.87$ $\mathrm{cm}^{3}$ [26]. Shyu et al., studied the orbital volume of the Taiwan population and reported a mean of $24.7 \pm 1.17$ $\mathrm{ml}$ and $24.3 \pm 1.51 \mathrm{ml}$ respectively for the right and left orbits in males. The mean female orbital volume in the right and left orbit was $21.1 \pm 1.30 \mathrm{ml}$ and $21.0 \pm 1.21 \mathrm{ml}$ respectively [23]. Chau et al. in Hong Kong Chinese observed that bony orbital volume was $22.2 \mathrm{ml}$ in males and $19.81 \mathrm{ml}$ in females [27], whereas in a study of Japanese subjects, it was found to be $23.6 \pm 2.0 \mathrm{~cm}^{3}$ in males and $20.9 \pm 1.3 \mathrm{~cm}^{3}$ in females [28]. In a study conducted by Acer et al., documented that the mean bony orbital volume of the right orbital cavity was $22.35 \pm 3.05 \mathrm{~cm}^{3}$ and $18.47 \pm 2.52 \mathrm{~cm}^{3}$ respectively for males and females. Similarly the mean orbital volume of the left orbital cavity for males and females was $22.71 \pm 2.80 \mathrm{~cm}^{3}$ and $18.16 \pm 2.52 \mathrm{~cm}^{3}$ respectively [29]. In the present study, the mean bony orbital volume on the right and left sides in males was $26.21 \pm 2.13 \mathrm{ml}$ and $25.96 \pm 2.16 \mathrm{ml}$, whereas in females was $24.07 \pm 2.20 \mathrm{ml}$ and $24 \pm 2.39 \mathrm{ml}$ respectively.

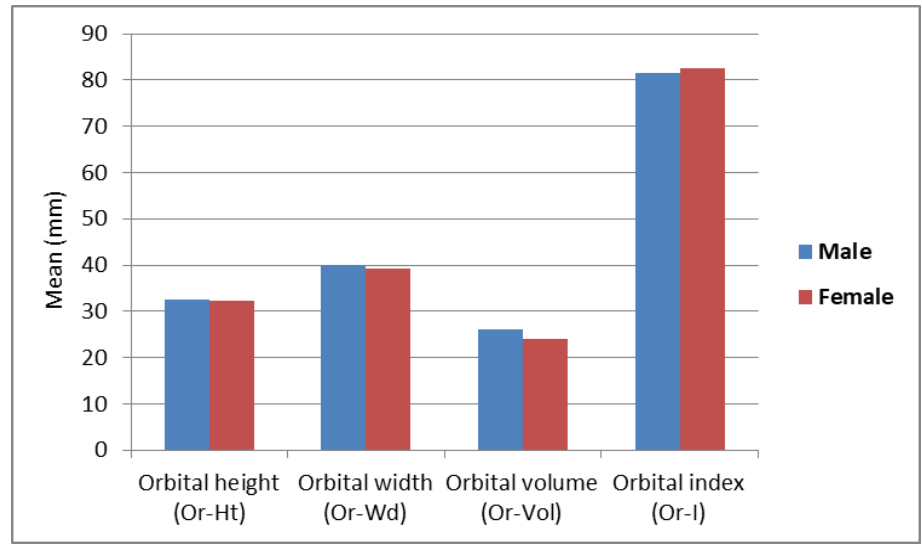

Fig-3: Bar diagram showing the Comparison of mean orbital morphometry values between male and female skulls

The present study result was found to be lesser than Fetouh and Erkoc, but greater than Shyu, Chau, Furuta and Acer. The variability in the results was due to the disparity in the methodology and the geographical position of the studies. The values of the measured parameters in the present study were greater in males than in females, which were statistically insignificant in height and width while being significant in volume (Figure-3). The discrepancy observed between the values on the right and left side of the calculated parameters could be due to the differential growth on both sides of the brain [30].

The relationship between the orbital height and the orbital width is determined by the orbital index (OI), which is defined as the ratio of the orbital height to the width multiplied by 100 . Using the orbital index as a reference, three orbit groups have been identified, megaseme describes an OI of 89 or over and microseme describes an OI of 83 or less, while mesoseme describes an OI between 83 to 89 [20,31]. The orbital index that determines facial shape varies among different population groups. It means that orbits with greater width than height will have smaller orbital indices, while those with larger orbital indices will have wider faces [18, 31].

The present study observed that the mean orbital index in males was $82.09 \pm 6.19 \mathrm{~mm}$ for the right side and $80.94 \pm 5.98 \mathrm{~mm}$ for the left side, while in females it was $82.18 \pm 5.00 \mathrm{~mm}$ for the right side and $82.89 \pm 5.71 \mathrm{~mm}$ for the left side. The gross orbital index was $81.51 \pm 6.11$ and $82.54 \pm 5.38$ respectively for males and females. This classified the orbital cavity of the North Indian population under microseme category.

Mekala et al., categorized the male and female orbital cavity under mesoseme with an average orbital index of 84.62 and 85.46 respectively in the South Indian population [20]. According to Narasinga et al. analysis in North Coastal Andhra Pradesh, the average orbital index for right and left orbits was 86.13 and 90.69 respectively, which listed right orbits as 
mesoseme and left orbits as megaseme [32]. For the Central Indian population, the orbital index was 84.39 $\mathrm{mm}$ on the right side and $84.57 \mathrm{~mm}$ on the left side, according to Aggarwal et al [33]. In a study by Gosavi et al., in the Maharashtra region classified the orbital cavity under the microseme with a mean orbital index of 81.88 , while it was 81.65 according to Kaur in the Punjab region [17, 18]. Alam et al., measured the orbital index in 50 skulls and observed that it was $82.60 \pm 4.43 \mathrm{~mm}$ on the right and $82.76 \pm 6.96 \mathrm{~mm}$ on the left [34]. In their analysis on the Egyptian skulls, Fetouh et al. recorded the orbital index as 82.20 \pm 2.97 $\mathrm{mm}$ on the right side and $82.81 \pm 3.02 \mathrm{~mm}$ on the left side in males and $84.13 \pm 3.76 \mathrm{~mm}$ on the right side and $82.88 \pm 3.31 \mathrm{~mm}$ on the left side in females [4]. An analysis carried out on the South Indian population recorded an orbital index of $84.62 \pm 8.21 \mathrm{~mm}$ in males and $85.46 \pm 5.93 \mathrm{~mm}$ in females [20]. Gopalakrishna $e t$ al., analysis in Indian population identified $79.69 \%$ of right orbit and $75 \%$ of left orbit under microseme, while $20.31 \%$ of right orbit and $25 \%$ of left orbit under mesoseme category [35].

There are variations in studies regarding the orbital index. The transformation of the facial skeleton into adult form involved several factors. While in utero the basic structure is determined in accordance with genetically programmed blueprint, it is modified preand postnatally via functional matrices that react to environmental and epigenetic influences such as ethnicity, racial and dietary history [36-39]. In addition, the practice of using a pillow or some other object to support the head while sleeping is also important [30, 40].

Knowledge of a specific region's orbital indices may be used as guidance for further research and care of patients with craniofacial deformities.

\section{CONCLUSION}

This study provides valuable baseline orbital morphometric data in the dry skull of North Indian adults for clinical and surgical care in ophthalmology, oral and maxillofacial surgery, neurosurgery, plastic surgery and designing eye protective equipment. These morphometric parameters are mandatory for the assessment of orbital cavity in several orbital diseases such as congenital orbital dysplasia, orbital fractures and intraorbital tumours. These metrics, in particular orbital index, can also be used in interpretation of fossil records, skull classification in forensic medicine and in exploring the trends in evolutionary and ethnic differences.

\section{REFERENCES}

1. Standring, S., Ellis, H., Healy, J. C., Johnson, D., Williams, A., \& Collins, P. eds. (2005). Gray's Anatomy: The Anatomical Basis of Clinical Practice. $39^{\text {th }}$ Edition, Elsevier, Churchill Livingstone, London, 511-513.
2. Karabekir, H. S., Gocmen-Mas, N., Emel, E., Karacayli, U., Koymen, R., Atar, E. K., \& Ozkan, N. (2012). Ocular and periocular injuries associated with an isolated orbital fracture depending on a blunt cranial trauma: anatomical and surgical aspects. Journal of CranioMaxillofacial Surgery, 40(7), e189-e193.

3. Patnaik, V. V. G., Sanju, B., \& Singla, R. K. (2001). Anatomy of the Bony Orbit- Some Applied Aspects. Journal of the Anatomical Society of India, 50(1), 59-67.

4. Fetouh, F. A., \& Mandour, D. (2014). Morphometric analysis of the orbit in adult Egyptian skulls and its surgical relevance. European Journal of Anatomy, 189(4), 303-15.

5. Ji, Y., Qian, Z., Dong, Y., Zhou, H., \& Fan, X. (2010). Quantitative morphometry of the orbit in Chinese adults based on a three- dimensional reconstruction method. Journal of Anatomy, 217(5), 501-506.

6. Xing, S., Victoria, G., Ronald, C., \& Wu, L. (2013). Geometric morphometric analyses of orbit shape in Asian, African, and European human populations. Anthropological Science, 121(1), 111.

7. Willa, R. T. (2004). Transethmoidal approach to the optic canal: Surgical and radiological microanatomy. Surgical Neurology, 62, 268-74.

8. Wandee, A. (2006). Suprorbital notch/foramen, Infraorbital foramen and mental foramen in Thais: Anthropometric measurements and surgical relevance. Journal of Medical Association of Thailand, 89(5), 675-682.

9. Bakholdina, V. (2008). Morphometric characteristics and typology of the human orbit, Morphologiia, 133(4), 37-40.

10. Chrcanovic, B. R., Abreu, M. H., \& Custodia, A. L. (2011). Morphometric analysis of the supraorbital and infraorbital foramina relative to surgical landmarks. Surgical and Radiologic Anatomy, 33, 329-335.

11. Buikstra, J. E., \& Ubelaker, D. H. (1994).Standards for data collection from human skeletal remains, Arkansas Archaeological Survey series, Fayetteville, 44.

12. Pickering, R. B., \& Bachman, D. C. (1997). The use of forensic anthropology. Boca Raton, FL: CRC Press, 84-86.

13. Bigoni, L., Veleminska, J., \& Bruzek, J. (2012). Three dimensional geometric morphometric analysis of craniofacial sexual dimorphism in a central European sample of known sex. HomoJournal of Comparative Human Biology, 61, 1632.

14. Ji, Y., Qian, Z., Dong, Y., Zhou, H., \& Fan, X. (2010). Quantitative morphometry of the orbit in Chinese adult based on a three- dimensional reconstruction method. Journal of Anatomy, 217, 501-506. 
15. Acer, N., Sahin, B., Ergur, H., Basaloqlu, H., \& Ceri, N. G. (2009). Stereological estimation of the orbital volume: a criterion standard study. Journal of Craniofacial Surgery, 20, 921-925.

16. Martins, C., Costa e Silva, I. E., Campero, A., Yasuda, A., Aguiar, L. R., Tatagiba, M., \& Rhoton, A. (2011). Microsurgical anatomy of the orbit: the rule of seven. Anatomy research international, 2011; 3, 1-14.

17. Gosavi, S. N., Jadhav, S. D., \& Zambre, B. R. (2014). A study of orbital morphometry in Indian dry skulls. Asian Journal of Biomedical and Pharmaceutical Sciences, 4 (29), 23-25.

18. Kaur, J., Yadav, S., \& Singh, Z. (2012). Orbital dimensions - A direct measurement study using dry skulls. Journal of Academia and Industrial Research, 1(6), 293-95.

19. Lal, N., Cornwall, J., \& Dias, G. J. (2016). Orbital indices in a modern Sinhalese Sri Lankan population. Anatomy, 10(3), 205-210.

20. Mekala, D., Shubha, R., \& Rohini, D. M. (2015). Orbital dimensions and orbital index: A measurement study on South Indian dry skulls. International Journal of Anatomy and Research, 3(3), 1387-91.

21. Sarkar, N., \& Mukhopadhyay, P. P. (2018). Determination of sex from the morphometry of orbits in adult skull of contemporary eastern Indian population. Egyptian Journal of Forensic Sciences, 8(61), 1-6.

22. Yonguc, G. N., Gocmen-Mas, N., Aksu, F., Edizer, M., Akyer, S. P., \& Karabekir, S. (2017). Assessment of the orbit morphometry on West Anatolian dry skulls. Folia Morphologica, 77, 105-109.]

23. Shyu, V. B. H., Hsu, C. E., Chen, C. H., \& Chen, C. T. (2015). 3D-Assisted Quantitative Assessment of Orbital Volume Using an OpenSource Software Platform in a Taiwanese Population. PLOS ONE, 10(3), e0119589.

24. Ukoha, U., Egwu, O. A., Okafor, I. J., Ogugua, P. C., Onwudinjo, O., \& Udemezue, O. (2011). Orbital dimensions of adult male nigerians: a direct measurement study using dry skulls. Int $J$ Biol Med Res, 2(3), 688-690.

25. Deveci, M., Ozturk, S., Sengezer, M., \& Pabuscu, Y. (2000). Comparison of pre-and postoperative orbital volume using three dimensional CT imaging in zygoma fracture patients. European Journal of Plastic Surgery, 23(8), 432-437.

26. Erkoc, M. F., Oztoprak, B., Gumus, C., \& Okur, A. (2015). Exploration of orbital and orbital softtissue volume changes with gender and body parameters using magnetic resonance imaging. Experiment and Therapeutic Medicine, 9(5), 1991-97.

27. Chau, A., Fung, K., Yip, L., \& Yap, M., (2004). Orbital development in Hong Kong Chinese subjects. Ophthalmic \& Physiological Optics, 24, 436-39.

28. Furuta, M. (2001). Measurements of orbital volume by computed tomography: especially on the growth of the orbit. Japanese Journal of Ophthalmology, 45(6), 600-06.

29. Acer, N., Demir, M., Ucar, T., Pekmez, H., \& Goktas, A. (2011). Estimation of the Eyeball and Orbital Volume Using the Cavalieri Principle on Computed Tomography Images. Balkan Medical Journal of Trakya University, 28, 184-88.

30. Teul, I., Czerwinski, F., Gawlikowska, A., Kurkiewicz, K. V., \& Stawinski, G. (2002). Asymmetry of the ovale and spinosum foramina in mediaeval and contemporary skulls in radiological examination. Folia Morphololgica, 61, 147-52.

31. Maharana, S. S., \& Agarwal, R. K. (2015). Variations in the dimensions of the orbit in the adult human skull (a dry bone study). International Journal of Recent Biotechnology, 3(3), 20-22.

32. Narasinga, R. B., \& Pramila, P. M. (2015). A study of Orbital Index in dry skulls of North Coastal Andhra Pradesh, International Journal of Basic and Applied Medical Sciences, 5(2), 1-3.

33. Agrawal, J., Gautam, D., Soutkke, V., \& Mourya, P. K. (2017). Morphometry of orbit from adult dry skull of Central Indian population. International Journal of Anatomy and Research, 5(4.3), 475659.

34. Alam, M.T., Rai, R., \& Singh, M. K. (2016). Orbital dimensions and orbital index of adult human dry skulls: A direct measurement study, 5(1), 523-24.

35. Gopalakrishna, K., \& Shenoy, M. K. (2015).The craniometrical study of orbital base of Indian population and its applied importance. Scholars Academic Journal of Biosciences, 3(7), 618-23.

36. Vioarsdottir, U. S., Higgins, P. O., \& Stringer, C. (2002). A geometric morphometric study of regional differences in the ontogeny of the modern human facial skeleton. Journal of Anatomy, 201(3), 211-29.

37. Krishan, K. (2007). Anthropometry in Forensic Medicine and Forensic Science-'Forensic Anthropometry'. The Internet Journal of Forensic Science, 2(1).

38. Farkas L. G., Posnick J. C., Hreezko T. M., \& Pron G. E. (1992). Anthropometric growth study of the head. Cleft Palate-Craniofacial Journal, 29 , 303-08.

39. Evereklioglu, C., Dogany, S., Er, H., Gunduz, A., Tercan, M., Balat, A. (2002). Craniofacial anthropometry in a Turkish population. Cleft palate craniofacial Journal, 39(2), 208-18.

40. Rossi, M., Ribeiro, E., \& Smith, R. L. (2003). Craniofacial asymmetry in development: An anatomical study. The Angle Orthodontist, 73.38185 . 